\title{
Aislamiento e Identificación de bacterias nativas con potencial probiótico en el camarón (Litopenaeus vannamei) cultivado en Honduras, 2018
}

Isolation and Identification of native microorganisms with potential probiotic in the shrimp (Litopenaeus vannamei) farmed in Honduras, 2018

DOI 10.5377pc.v0i16.8096

Erick Joaquín Ardón Larios, Christian Rolando Hernández Coello, Dunia Yessenia López Sosa Liliam Carina Marroquín Tejeda ${ }^{2}$

\section{RESUMEN}

El uso de probióticos se vuelve cada día más común en las producciones acuícolas tanto para la prevención de enfermedades como para el mejoramiento de la calidad de agua y fondos de los sistemas de producción, minimizando el uso indiscriminado de antibióticos, así como mejorando el medio ambiente. Estos probióticos deben adaptarse al medio lo que muchas veces no permite observar resultado favorable a corto plazo. El objetivo fue aislar e Identificar bacterias nativas con características probióticas presentes en el camarón blanco Litopenaeus vannamei el uso de microorganismos nativos nos permitirá optimizar el tiempo de adaptación ya que no tendrán que adaptarse pues vivirán en su hábitat natural. La investigación es descriptiva experimental, se realizaron muestreos aleatorios simples con selección al azar de 60 camarones de cultivo a los cuales se les extrajo el tracto gastrointestinal se maceraron para ser sembraron en medios cultivo selectivos Agar Tiosulfato Citrato Bilis Sacarosa (TCBS), Agar Papa Dextrosa (PDA), Agar MRS para lactobacillus y otras bacterias ácido lácticas, Agar Actinomicetos y Müeller Hinton como medio no selectivo. Los microorganismos que fueron aislados e identificados se llevaron a producción en biorreactor para comprobar las características principales como ser crecimiento rápido y fáciles de cultivar. Se aislaron bacterias de la especie Bacillus subtilis y

${ }^{1}$ Estudiantes de la carrera Ingeniería en Ciencias Acuícolas y Recursos Marino Costero; CURLP-UNAH: eardon@unah.hn; coello.christian@unah.hn; dylopezs@unah.hn

${ }^{2}$ Asesora principal de investigación, Coordinadora de la carrera de Ingeniería en Ciencias Acuícolas y Recursos Marino Costeros, CURLP-UNAH: liliam.marroquin@unah.edu.hn 
Actinomicetos las cuales presentan características con potencial probiótico y cumplen con la característica de ser de cultivo poco exigente y con excelente multiplicación.

Palabras clave: actinomicetos, Bacillus subtilis, Litopenaeus vannamei, probióticos, tracto gastro intestinal.

\section{ABSTRACT}

The use of probiotics becomes more common every day in aquaculture productions, for the prevention of diseases as the improvement of water quality and funds of production systems, minimizing the indiscriminate use of antibiotics, like improving the environment. These probiotics must be adapted to the medium that is why often we cannot see favorable short-term results. The objective was the isolation and identification of native microorganisms with potential probiotic present in the white shrimp Litopenaeus vannamei, these native microorganisms will allow us to optimize the adaptation time as they will not have to adapt because they will live in their native environment. This is a descriptive, experimental investigation; simple random sampling was done by random selection of 60 shrimp from which the gastrointestinal tract (GIT) was extracted and macerated to be planted in the selective culture media Thiosulfate Citrate Biles Sucrose Agar (TCBS), Man Rogosa and Sharpe (MRS); Potato dextrose Agar (PDA), Isolation of Actinomycetes Agar and Müeller Hinton like a non-selective culture media. The microorganisms that were isolated and identified were cultured in a bioreactor to identify the principal characteristics like fast growing and easy culture. The microorganisms that were identified were Bacillus subtilis and Actinomycetes, they have characteristics like potential probiotics. These microorganisms have the characteristics to be undemanding and with excellent growing.

Keywords: actinomycetes, Bacillus subtilis, gastrointestinal tract, Litopenaeus vannamei, probiotics. 


\section{INTRODUCCION}

A nivel mundial, la acuicultura se ha convertido en una importante industria proveedora de alimentos de alto valor nutricional y generadora de empleo e ingresos en los países tanto desarrollados, así como en los que se encuentran en vías de desarrollo. Según cifras de la FAO el suministro mundial de alimentos pesqueros ha aumentado considerablemente en las cinco últimas décadas, con una tasa media de crecimiento del 3,2 por ciento anual. Con la creciente intensificación y comercialización de la producción acuícola a nivel internacional y local, aparecen enfermedades e infecciones que se convierten en un problema para el cultivo de muchas especies acuáticas (García Naranjo, A Gutiérrez, \& A David RB, 2015).

Para erradicar estas enfermedades se comenzó a usar antibióticos sin embargo el uso abusivo de estos provocó tolerancia en los microorganismos patógenos. El fenómeno de la resistencia a los antibióticos es una amenaza global, que afecta a todos los ámbitos (medicina, veterinaria, seguridad alimentaria y medioambiente) y es una preocupación de carácter mundial y por ello se requiere la adopción de medidas armonizadas y globalizadas para su control. Ya en el año 2001, la Organización Mundial de la Salud (OMS) apuntaba hacia el aspecto global de la resistencia a los antimicrobianos, definiéndolo como un problema complejo. Su uso está totalmente prohibido desde 2006 en toda la Unión Europea (UE) por sus posibles riesgos para la salud humana; sin embargo, en otros países, la normativa en alimentación animal ha sido más permisiva, este es el caso de Estados Unidos (EEUU), donde todavía se emplean los antibióticos en alimentación animal (Torres Manrrique, 2012)

A raíz de esta problemática surge la necesidad de utilizar los probióticos. En las últimas décadas, la comunidad científica examina cuidadosamente el rol y los posibles efectos del uso de probióticos en acuicultura como una alternativa viable al uso de antibióticos, debido a que el beneficio que juegan las bacterias no patógenas para proteger a su huésped contra infecciones es enorme, así como los efectos positivos sobre el crecimiento, supervivencia, y en general, sobre el bienestar animal (Sarroza, y otros, 2012)

Considerando que esto último asegura una buena producción y por consiguiente se garantiza una economía exponencial. La investigación de probióticos en la acuicultura se encuentra a un en sus primeras fases de crecimiento, por lo que mucho trabajo al respecto es necesario. Los principales grupos bacterianos que se han probado como probióticos en cultivo de peneidos, cangrejos, moluscos (ostión) y peces princi- 
palmente marinos, han sido Vibrios, Pseudomonas, Bacilos, Levaduras y Lactobacilos (Ronsón-Paulín \& Medina-Reyna, 2002).

La mayoría de los microorganismos probióticos propuestos para acuicultura pertenecen a las BAL, de las cuales los géneros más utilizados son Lactobacillus y Lactococcus. Diversos estudios reportan el uso de BAL en langostinos. (Melgarejo Velazques , 2016)

La micro biota bacteriana está relacionada con el tracto digestivo de los animales acuáticos, cuya composición genérica son diferentes entre sí, debido a una serie de factores como condiciones ambientales del lugar de captura de los animales; diferente a la clasificación taxonómica de las bacterias, en los métodos de aislamiento: y la edad y estado de desarrollo de la especie. (Melgarejo Velazques , 2016)

Por medio de un correcto aislamiento e identificación bacteriano se pueden determinar si estas bacterias presentan características que pueden ser aprovechados como un potencial probiótico utilizado por la industria camaronera. El uso de este beneficiaría al medio marino, ya que por ser bacterias nativas no alterarían el ecosistema acuático.

La importancia de utilizar probióticos radica en que estos pueden mejorar la disponibilidad de nutrientes debido a las enzimas exógenas secretadas en el intestino del huésped 0 a las enzimas endógenas disponibles en las células bacterianas y se liberan cuando se lisan por el efecto del medio ácido del estómago anfitrión. Ambos tipos de enzimas pueden aumentar la actividad digestiva y la degradación de los compuestos de la dieta del animal probado incluso si no digerible por su propia maquinaria enzimática. (Sánchez-Ortiz, y otros, 2015)

Con estos resultados tendremos la oportunidad de nuevas alternativas en el empleo de probióticos. Es importante indicar que la fuente de extracción de la especie tendrá procedencia nativa, lo cual aparte de identificar un potencial probiótico para la industria camaronera del Sur de Honduras permitirá la identificación de las bacterias que habitan en el Tracto Gastro Intestinal (TGI) del camarón blanco.

Considerando todos los problemas que pueden ocasionar el uso indiscriminado de los antibióticos, es importante buscar alternativas que aseguren la sostenibilidad en producción acuícola y mitiguen el impacto de la aparición de enfermedades que puedan ocasionar la pérdida del cultivo. Es por esta razón que las investigaciones en esta área son de gran importancia para la acuicultura, ya que por medio de los probió- 
ticos se puede ser amigable con el ecosistema acuático.

Las investigaciones con el fin de extraer probióticos a base de bacterias que habiten nativamente en el TGI de las especies acuícolas son relativamente nuevas y todavía hay mucho que explorar para lograr determinar cuáles de estas bacterias pueden ser un potencial probiótico para la acuicultura.

El objetivo general de la investigación fue aislar e Identificar bacterias con características probióticas presentes en el camarón blanco Litopenaeus vannamei.

\section{MATERIALES Y METODOS}

\section{Delimitación del objeto de estudio}

Ilustración 1. Ubicación geográfica del laboratorio de Ciencias Biológicas del CURLP-UNAH. (Google maps)

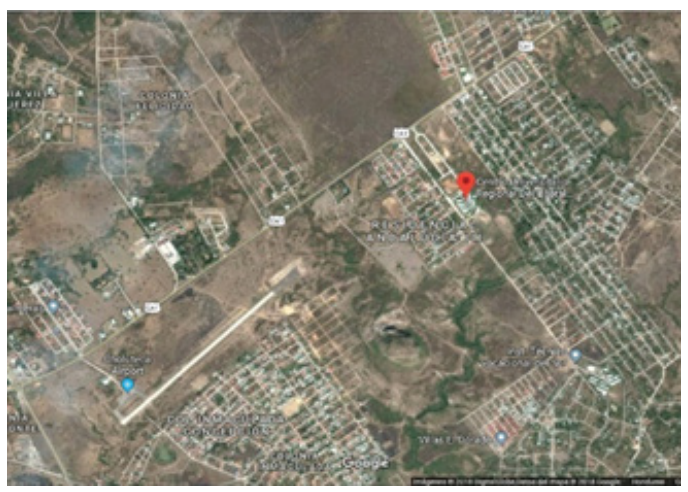

La investigación se desarrolló en el Laboratorio de Ciencias Biológicas del Centro Universitario Regional del Litoral Pacífico CURLP-UNAH (13.327372 N, $-87.135590 \mathrm{~W}) 5 \mathrm{~km}$ Salida a San Marcos. Tuvo un periodo de 10 semanas de estudio comprendidas entre el 26 de febrero al 27 de abril del año 2018.

\section{Recolección de organismos}

Los camarones de la especie Litopenaeus vannamei fueron donados por una finca camaronera ubicada en el Golfo de Fonseca, Honduras. (13.201691 N, -87.569053 W). Se capturaron 60 camarones de 7 gramos seleccionados de una laguna al azar 
pertenecientes de la finca camaronera. La captura consistió en 6 muestreos aleatorios simples en diferentes puntos de la laguna.

\section{Transporte de organismos}

Fueron transportados a las instalaciones del Laboratorio de Ciencias Biológicas del CURLP-UNAH en un recipiente con agua de la laguna al cual se le agregó hielo con el fin de bajarles metabolismo a los organismos para asegurar que estos al momento de estar en el laboratorio estuvieran vivos.

\section{Extracción del Tracto Gastrointestinal}

Para la extracción del TGI del camarón se utilizó el medio líquido Agua Peptonada con el propósito de enriquecer la flora bacteriana presente en el animal. Al momento de realizar la extracción se realizaron 6 pools microbiológicos que estaba compuesto por los TGI de 10 animales en cada uno, cada TGI fue macerado con y agregado al medio líquido que posteriormente fue sembrado en diferentes medios de cultivos con el fin de aislar bacterias.

\section{Aislamiento bacteriano y Siembra}

Con los 6 pools microbiológicos listos se procedió a realizar siembras en los medios de cultivo selectivos: Tiosulfato Citrato Bilis Sacarosa (TCBS), Man Rogosa and Sharpe (MRS); Papa Dextrosa Agar (PDA); Agar Aislamiento de Actinomicetos y en el medio de cultivo nutritivo: Müeller Hinton. Cada procedimiento de siembra se realizó por duplicado utilizando las técnicas de siembra Frobisher y en cruz.

\section{Identificación bacteriana}

La identificación de los microorganismos que crecieron en los medios de cultivo se hizo mediante la morfología colonial y celular de las colonias que estaban presentes en los medios.

\section{Pruebas de confirmación}

Se realizaron las de confirmación microbiológicas estándares pasa la confirmación de bacterias, dentro de las pruebas realizadas estaban: Coloración Gram, Prueba de oxidasa, Tolerancia al pH, y se emplearon las tablas de identificación descritas en el Manual de Determinación Bacteriológica de Bergey's. 


\section{Prueba de Antibiograma}

A los microorganismos que presentaron características probióticas se les realizó la prueba del antibiograma con el objetivo de determinar la eficacia de los microorganismos ante un microorganismo patógeno.

\section{Levantamiento de probiótico}

Una vez que los microorganismos estaban identificados se les realizó la fase de levantamiento con el propósito de llevar el cultivo a una producción en mayor escala para establecer si estos podían crecer en biorreactores específicos para cada microorganismo.

Para empezar la base de levantamiento se hicieron 4 medios biorreactores en donde cada 2 biorreactores eran específicos para cada microorganismo aislado. Como biorreactores se utilizaron: $50 \mathrm{ml}$ del medio Base de Casman, para levantamiento inicial de Bacillus subtilis.

Para llevar este microorganismo a mayor escala se realizó un biorreactor elaborado a base de 10 gramos harina de arroz suplementado con $5 \mathrm{ml}$ melaza y 4 litros de agua destilada.

Para Actinomicetos se utilizó como biorreactor inicial el medio Bennett, cuya composición es: caseína $2 \mathrm{~g}$; extracto de carne $1 \mathrm{~g}$; extracto de levadura $1 \mathrm{~g}$; glucosa $10 \mathrm{~g}$; agua destilada 1 litro, pH 7,2. (Uzcátegui Negrón, Serrano, \& Panizo, 2013)

Para levantamiento a mayor escala se utilizó: el medio de harina de avena, cuya composición es: harina de avena $20 \mathrm{~g}$ (cocinada en 1 litro de agua destilada por 20 minutos, filtrada a través de un paño, una vez filtrado se le agregó agua destilada para recuperar el volumen filtrado, se le agregó una mezcla de vitaminas de $3.7 \mathrm{mg}$ y $1 \mathrm{ml}$ de sln salina. [ ${ }^{*} \mathrm{FeSO} 4 \otimes 7 \mathrm{H} 2 \mathrm{O} 0.1 \mathrm{~g}, \mathrm{MnCl} 20.1 \mathrm{~g}, \mathrm{ZnSO}{ }^{*} 7 \mathrm{H} 2 \mathrm{O} 0.1 \mathrm{~g}$, agua destilada $100 \mathrm{ml}$.]. Al medio se le agregó $50 \mathrm{mg}$ de dicromato de potasio y $1 \mathrm{mg}$ de penicilina. (Jiang, Li, Chen, \& Jiang, 2016)

\section{Diseño experimental}

Se implemento diseño experimental por fase o etapas, segmentando cada parte de la investigación para un mejor aislamiento, purificación e interpretación de resultados. 


\section{Ilustración 2. Diseño Experimental. Elaboración propia}

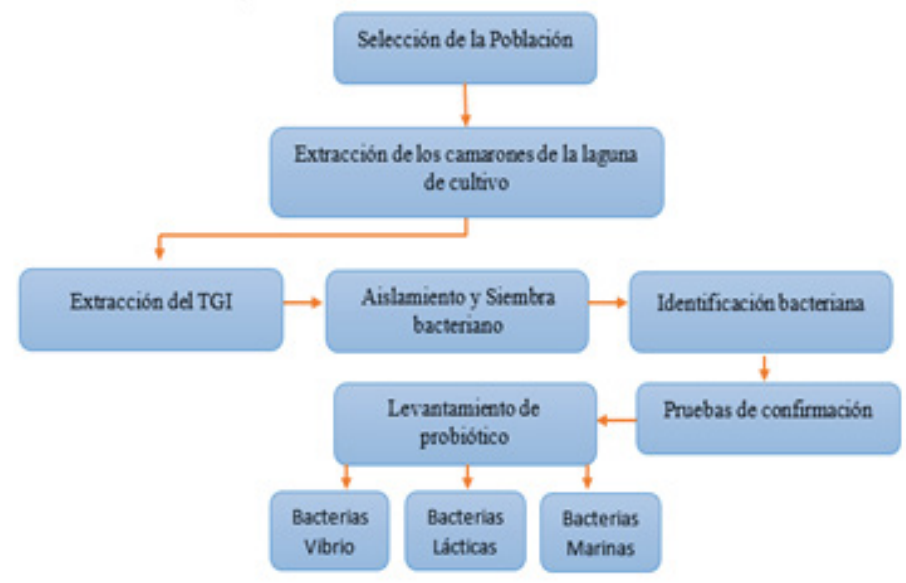

Fuente: Creación propia

\section{RESULTADOS}

\section{Aislamiento bacteriano}

\section{Tabla 1. Crecimiento en Medios de Cultivo}

\begin{tabular}{|l|c|c|}
\hline \multicolumn{3}{|c|}{ Reporte de Crecimiento } \\
\hline Medio & $\begin{array}{l}\text { Si hubo } \\
\text { crecimiento }\end{array}$ & $\begin{array}{l}\text { No hubo } \\
\text { crecimiento }\end{array}$ \\
\hline TCBS & $\mathrm{X}$ & \\
\hline MRS & & $\mathrm{X}$ \\
\hline PDA & $\mathrm{X}$ \\
\hline $\begin{array}{l}\text { Agar Aislamiento de } \\
\text { Actinomicetos }\end{array}$ & $\mathrm{X}$ & \\
\hline Müeller Hinton & $\mathrm{X}$ \\
\hline
\end{tabular}

Fuente: Creación propia

De los aislados se separaron las cepas que por morfología colonial presentaban características probióticas a las que se les realizó coloración de Gram y procediendo a la identificación bioquímica de acuerdo con el Manual de bacteriología de Bergey's de las colonias aisladas se logró identificar Bacillus subtilis y una especie del género Actinomicetos las cuales fueron seleccionadas para levantar probiótico por ser las colonias con mayor prevalencia en los medios de cultivo utilizados. 


\section{Tolerancia a pH}

A los microorganismos aislados e identificados se les realizó la prueba de tolerancia al pH para determinar si estas pueden crecer en condiciones similar al pH gástrico, los cuales demuestran tolerancia a los rangos de $\mathrm{pH}$ de 4 a 5 para actinomicetos y entre 5 a 6 para $B$. subtilis. Con estos resultados podemos decir que estas bacterias tienen resistencia a la acidez, ya que no se ven afectadas por pH de 4 y 5 pero si el $\mathrm{pH}$ disminuye de estas concentraciones estas no resisten.

\section{Coloración Gram}

\section{Ilustración 3. Morfología celular de Bacillus subtilis}

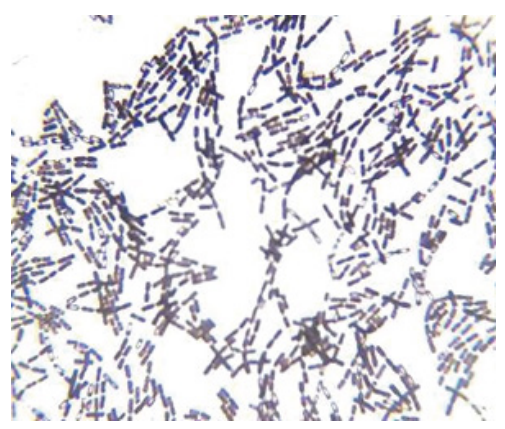

Mediante pruebas de confirmación se determinó que uno de los microorganismos purificados fueron Bacillus subtilis cuya morfología colonial es Colonias, de 2 a $4 \mathrm{~mm}$ de diámetro, beta hemolíticas con hemólisis completa, que pueden ser de aspecto liso, mucoide o rugoso; los bordes pueden ser ondulados o extendidos en el medio y ocasionalmente dan la apariencia de cultivos mixtos. (Realpe, Hernández, \& Agudelo, 2002). Su morfología celular es: bacilos Gram positivo esporulados.

\section{Ilustración 4 Morfología celular del género Actinomicetos}

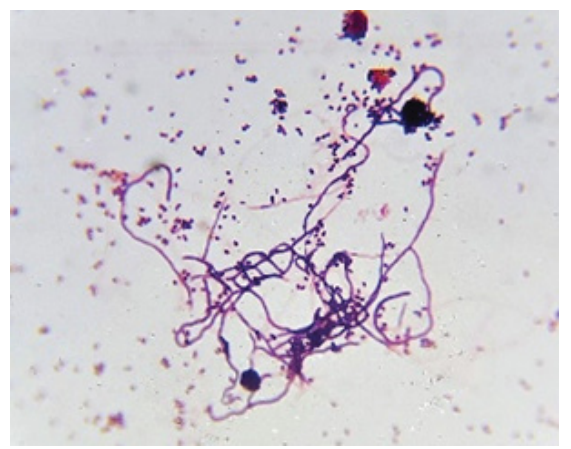


Macroscópicamente, las colonias en medios sólidos son de aspecto seco, costrosas y pulverulentas, las cuales pueden presentar de diferentes colores. En el caso de medios líquidos predomina la formación un sedimento de aspecto algodonoso, notándose el medio de cultivo transparente. (Tarazona Janampa , 2017). Celularmente su morfología es: Son microorganismos Gram positivos, presentan largas hifas filamentosas (entre 0,5 y 2,0 $\mu \mathrm{m}$ ), de diámetro menor al de los hongos, crecen en forma de red llamadas micelios, que pueden ser de dos tipos: micelio vegetativo y micelio aéreo. (Tarazona Janampa , 2017)

\section{Levantamiento de Probiótico}

Los microorganismos identificados se llevaron a la producción en escala en medio líquido, lo que nos permitió verificar si los microorganismos aislados cumplen con la característica de ser de fácil cultivo y rápido crecimiento esto se logró mediante la evaluación del cultivo en medios líquidos con el cuál se midió el crecimiento del microorganismo durante 18 horas continuas los resultados fueron los siguientes:

a) Cultivo de Bacillus subtilis

\section{Gráfico 1. Crecimiento de Bacillus subtilis en el biorreactor inicial}

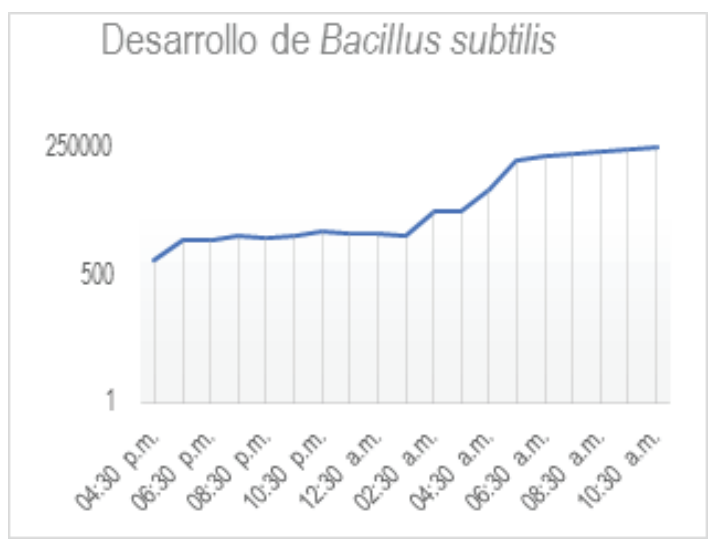

Los resultados evidencian que la fase lag tiene una duración de 9 horas, la fase exponencial o logarítmica dura alrededor de 8 horas por lo que para Bacillus subtilis se cumple la característica de ser un microorganismo de rápido crecimiento y a la vez fácil de multiplicar ya que demuestra no ser exigente para ser cultivado. 
b) Cultivo de Actinomicetos

Gráfico 2. Crecimiento de Actinomicetos en el biorreactor inicial

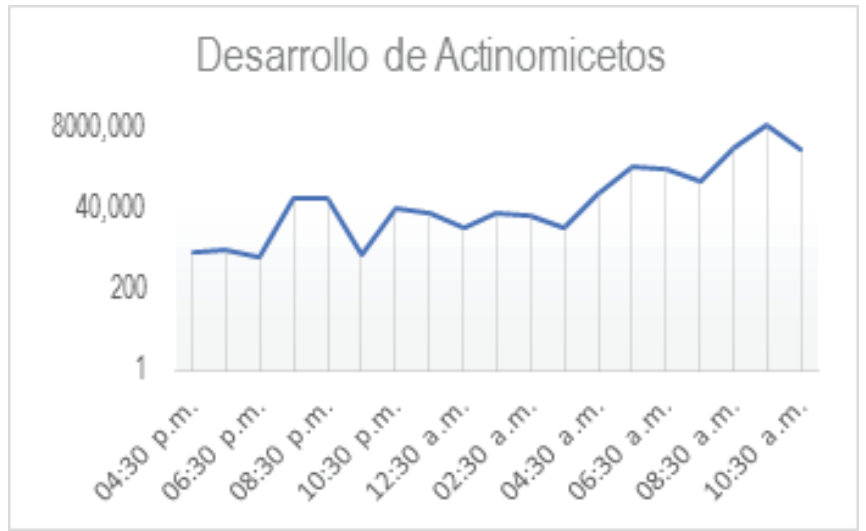

La fase de adaptación para los actinomicetos es mayor, ya que el crecimiento de estos microorganismos es más lento, sin embargo, mediante conteo cada 24 horas se demuestra que cuando el crecimiento de este microorganismo empieza, lo hace de manera rápida.

Comportamiento de microorganismos en biorreactor para cultivo a escala

a) Comportamiento de Bacillus subtilis en biorreactor

Gráfico 3. Comportamiento de Bacillus subtilis en biorreactor a escala

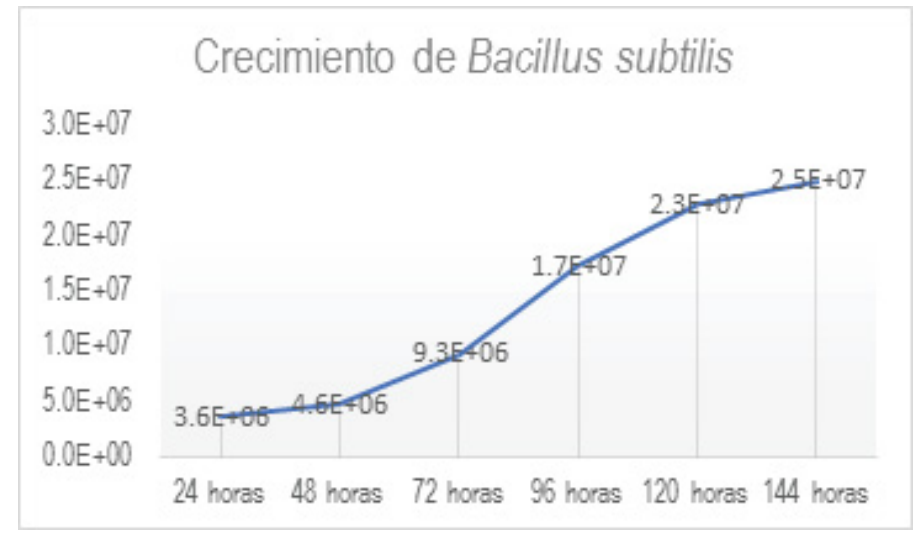


La aceptación de los microorganismos en el medio elaborado a base de harina de arroz y melaza fue favorable ya que, mediante al gráfico de crecimiento número 3 se

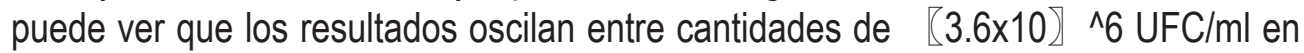
las primeras 24 horas de siembra hasta datos de $(2.5 \times 10 \rrbracket \wedge 7 \mathrm{UFC} / \mathrm{ml}$ pasadas 144 horas.

b) Comportamiento de Actinomicetos en biorreactor

\section{Gráfico 4. Comportamiento del género Actinomicetos en el biorreactor a escala}

\section{Crecimiento de Actinomicetos}

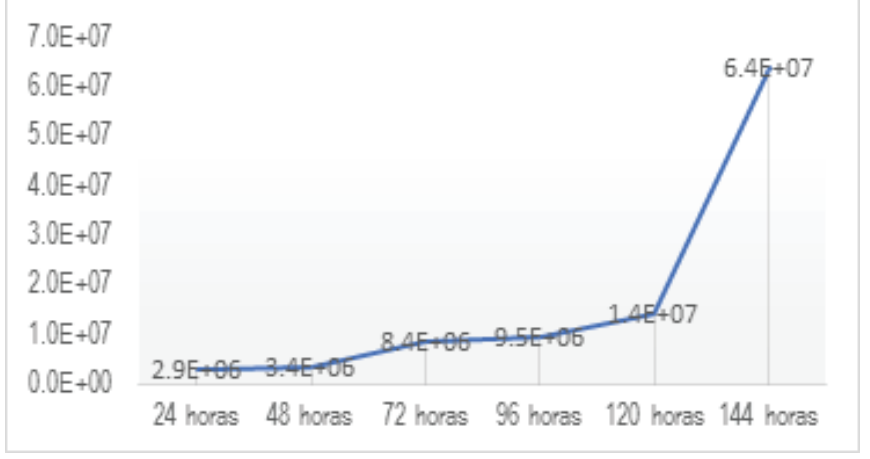

Debido que el crecimiento de estos microrganismos es más lento se evidencia moderado crecimiento en las primeras 120 horas de siembra, estableciendo que el crecimiento exponencial para los actinomicetos se empieza a ver pasadas 144 horas de siembra pasando de datos numéricos de $\llbracket 2.9 \times 10 \rrbracket{ }^{\wedge} 6 \mathrm{UFC} / \mathrm{ml}$ en las primeras 24 horas a lecturas del $[6.4 \times 10 \rrbracket \wedge 7 \mathrm{UFC} / \mathrm{ml}$

\section{DISCUSION}

Los microorganismos aislados cumplen con características como ser rápido crecimiento y adaptación eficaz al medio de cultivo elaborado para llevar el probiótico a escala en biorreactor.

De las especies de microorganismos aislados se puedo establecer mediante conteos al microscopio que el crecimiento de Bacillus subtilis es más rápido en comparación a las bacterias del género Actinomicetos, sin embargo, cuando este empieza a crecer lo hace de manera acelerada. 
Las especies estudiadas pueden colonizar el TGI de los organismos y ser utilizadas como probióticos, ya que estas son capaces de tolerar pH gástrico.

Con las especies que no se pudieron aislar, se consideraría que pudo verse afectado por contaminación cruzada o factores y condiciones dentro del laboratorio donde se llevó a cabo la investigación.

\section{CONCLUSIONES}

Dentro de la especie en estudio habitan en su TGI microorganismos que son capaces de inhibir el crecimiento de bacterias que son patógenas para los sistemas acuícolas. De los microorganismos que se esperaban aislar e identificar, sólo se pudieron purificar dos de ellos, una especie del género Actinomicetos y Bacillus subtilis; el género Actinomicetos se identificó mediante su morfología celular y colonial y Bacillus subtilis se identificó mediante bioquímica establecida en el manual de bacteriología de Bergey's.

Las especies de bacterias que se lograron aislar e identificar son de gran importancia biotecnológico e interés industrial.

\section{RECOMENDACIONES}

Se recomienda llevar esta investigación a una segunda fase donde se pueda determinar la eficacia de los probióticos elaborados a mayor escala para establecer el efecto antagónico en las lagunas de producción.

Los Actinomicetos y Bacillus subtilis actualmente son requeridos como una alternativa biológica que no es nociva para el medio ambiente, por ello se recomienda que los probióticos sean utilizados con mayor frecuencia en los sistemas de producción acuícolas para reducir la incidencia de enfermedades y mejorar la calidad del agua en los sistemas. 


\section{REFERENCIAS BIBLIOGRÁFICAS}

García Naranjo, R., A Gutiérrez, L., \& A David RB, C. (24 de diciembre de 2015). El uso de los probióticos en la industria acuícola. Alimentos hoy, 23(36), 165-178. Obtenido de http://www.alimentoshoy.acta.org.co/index.php/hoy/article/view/354/304

Jiang, Y., Li, Q., Chen, X., \& Jiang, C. (11 de febrero de 2016). Isolation and Cultivation Methods of Actinobacteria. INTECH, 39-57. doi:10.5772/61457

Melgarejo Velazques , G. Y. (2016). Caracterización de bacterias ácido lácticas aisladas del intestino de Litopenaeus vannamei cultivados en sistema intensivo en Tumbes - Perú y su potencial uso como probióticos. Nuevo Chimbote. Obtenido de http://repositorio.uns.edu.pe/bitstream/handle/UNS/2580/42780.pdf?sequence=1\&isAllowed=y

Realpe, M. E., Hernández, C. A., \& Agudelo, C. I. (2002). Especies del género Bacillus : morfología macroscópica y microscópica. Bogotá.

Ronsón-Paulín, J. Á., \& Medina-Reyna, C. E. (22 de 8 de 2002). Probióticos en la acuicultura. Santiago de Compostela, La Coruña, España. Obtenido de UMAR : http://www.umar.mx/revistas/18/probioticos.pdf

Sánchez-Ortiz, A. C., Luna-González, A., Campa-Córdova, Á. I., Escamilla-Montes, R., Flores-Miranda, M. D., \& Mazón-Suástegui, J. M. (2015). Isolation and characterization of potential probiotic bacteria from pustulose ark (Anadara tuberculosa) suitable for shrimp farming. (E. Rudolph, Ed.) Scielo, 43(1). Obtenido de http://www.scielo.cl/scielo.php?script=sci_arttext\&pid=S0718-560X2015000100011\&lng=es\&nrm=iso\&tlng=en

Sarroza, L., Padilla, D., Acosta, F., Román , L., Acosta, B., \& Real, F. (2012). Uso de probióticos en Acuicultura. Canaria De Las Ciencias Veterinarias, 50-53. Obtenido de https://acceda.ulpgc.es:8443/bitstream/10553/12399/1/0280574_0006_0010.pdf

Tarazona Janampa , U. I. (2017). Caracterización de actinomicetos de sedimento marino y su potencial actividad antagonista frente a Vibrio sp. aislados de Litopenaeus vannamei. Tesis, Universidad Nacional Mayor de San Marcos, Lima. Obtenido de http://cybertesis.unmsm.edu.pe/handle/cybertesis/5704

Torres Manrrique, C. (31 de 10 de 2012). La Resistencia Bacteriana a los Antibióticos, Siete Décadas Después de Fleming. Zaragoza. Obtenido de http://www.academiadefarmaciadearagon.es/docs/Documentos/Documento48.pdf

Uzcátegui Negrón, M., Serrano, J. A., \& Panizo, M. M. (24 de septiembre de 2013). Condiciones de cultivo que fomentan la producción de sustancias antimicrobianas en actinomicetos patógenos y del suelo. Revista de la Sociedad Venezolana de Microbiología, 33(2), 134-139. Obtenido de http://www.scielo.org.ve/scielo.php?script=sci_arttext\&pi$d=\$ 1315-25562013000200009$ 